\title{
ESCÂNDALO E CORRUPÇÃO: DA RECRIAÇÃO DO INVISÍVEL NOS MASS MEDIA ${ }^{1}$
}

\author{
Joaquim Braga ${ }^{2}$
}

Resumo: $\mathrm{O}$ fenómeno da corrupçáo não pode ser pensado sem a inclusão das suas potencialidades simbólicas. A informaçáo que, pela acção dos mass media, aparece construída sob a forma de escândalo, acaba por determinar a própria construção da sua natureza factual. Logo, aqui impera a questão de saber por que é que as práticas corruptas favorecem o discurso do escândalo, bem como a legitimação dos mass media como instrumentos de objectivação dos comportamentos ilícitos. Procurar-se-á ponderar essas questôes, mediante a formulaçáo de uma estética da "invisibilidade" inerente aos meios de comunicaçăo, que é, por sua vez, reforçada pelas potencialidades discursivas das práticas corruptas.

Palavras-chave: Corrupçâo. Escândalo. Invisibilidade. Mass media. Observação.

\section{INTRODUÇÃo}

Apercebendo-se da relevância da corrupção como forma de observação para a ordem social, a sociedade moderna gerou formas de comunicação que tornam visíveis a negação e a supressão da própria ordem. Trata-se de formas contrafactuais, com a capacidade de virtualizar as possibilidades que não correspondem aos modelos sociais reconhecidos e que permitem, por seu turno, tornar perceptíveis todos os eventos que náo devem ser expectáveis,

\footnotetext{
${ }^{1} \mathrm{O}$ presente texto segue o perfil ortográfico do português europeu.

2 Universidade de Coimbra, Instituto de Estudos Filosóficos (IEF), Departamento de Filosofia, Comunicação e Informação, Coimbra - Portugal. (D) https://orcid.org/0000-0003-3516-661X E-mail: bragajoaquim77@gmail.com
}

https://doi.org/10.1590/0101-3173.2021.v44n1.09.p125

\section{(i)}


que não devem pôr em risco a normalidade vigente. Analisado segundo o seu conceito tradicional, o fenómeno da corrupção encontra-se ligado a uma práxis entre dois agentes - corruptor e corrompido -, considerada, na maior parte das vezes, moral e judicialmente condenável. Todavia, o fenómeno da corrupção parece, hoje em dia, ter ultrapassado o nível da práxis, situandose, cada vez mais, na esfera da lexis, no domínio social da sua construção simbólica, discursiva e extradiscursiva.

A "visibilidade" tem sido, até hoje, um dos conceitos basilares na análise da teoria dos mass media, impondo-se, sob várias formas de manifestação, como aquele que melhor define os processos de mediatização das esferas pública e privada. Se, num primeiro momento, nada parece pôr em causa a legitimidade de tal pressuposto, uma vez que ambas as esferas se encontram sob um amplo escrutínio e dele também dependem para engendrar focos de publicitação, num segundo momento, porém, mais propenso à reflexão sobre a constituição estrutural dos órgãos de comunicação social, revela-se o conceito de visibilidade ainda escassamente desenvolvido, para poder incluir todas as dinâmicas de produção e recepção da informação mediática. Quer em obras individuais (THOMPSON, 1995, 2000), quer em obras colectivas (TUMBER; WAISBORD, 2019), é assaz nítida a tendência reflexiva de circunscrever a mediatização dos comportamentos socialmente reprováveis e qualificados de escandalosos - como é o caso da corrupção - a processos de ampliação do visível.

Como se intentará mostrar, tornar visivel é, apenas, um dos lados da visibilidade. A construção do real levado a cabo pelos mass media ${ }^{3}$ obedece, estruturalmente, à dinâmica bipolar da visibilidade: cada segmento de informaçáo náo só torna visível o evento em causa, como, igualmente, o inscreve fora do espaço ainda não diferenciado da invisibilidade. Essa dupla condição da informação de massas mostra-se deveras necessária

\footnotetext{
${ }^{3}$ Neste contexto analítico, por mass media entendemos todos aqueles artefactos, analógicos e digitais, de informação e comunicação que, utilizados tanto pela imprensa e a indústria do entretenimento em geral quanto pelas demais instituiçốes culturais de transmissão de conhecimento, suportam um espectro comunicativo profissionalizado e regulamentado e aspiram a um amplo alcance informativo. Apesar da abrangência semântica do termo, daremos, ao longo da nossa reflexão, especial relevância ao perfil simbólico dos mass media traçado pela imprensa noticiosa, a qual abrange as áreas do jornalismo impresso, radiofónico e televisivo. Hodiernamente, nem sempre as fronteiras entre as formas de informação são claras. Por isso, é, também, a pensar nesse facto que o termo mass media deve ser distinguido do termo self media, que pressupóe, quer ao nível da emissão, quer ao nível da recepção, um acoplamento estreito das possibilidades de comunicação - nomeadamente as do digital - com as possibilidades de informação individualizadas, sem escrutínio prévio requerido.
} 
para determinar o grau de novidade do evento, diminuindo, por extensão, o seu potencial grau de redundância perante os outros eventos que são, simultaneamente, tornados visíveis.

Num universo mediático em que o fluxo de informação ultrapassa, muitas vezes, o registo espácio-temporal dos próprios eventos, nem sempre, porém, nele existe espaço de inscrição para a dimensão do invisível. Esta tende a ser menos sugestiva, quanto maior for o espectro remissivo da informação. Por um lado, a capacidade da informação de gerar comunicação multiplica os nexos de interacção entre emissores e receptores, mas, por outro, enfraquece a génese e a incidência empíricas dos eventos em causa. Enquanto produto de um conjunto de selecçôes, cada evento é uma espécie de "recorte" de um vasto campo de possibilidades informativas, estando, desde logo, subordinado às especificidades materiais e simbólicas do médium de transmissão utilizado pelos órgãos noticiosos. O médium nunca é um simples artefacto (audiovisual, radiofónico, por exemplo), nem pode, unicamente, ser definido pela sua natureza tecnológica. Dependendo das modalidades sensoriais que pressupóe e envolve, cada médium se encontra, de igual modo, sujeito às formas como é materialmente configurado e articulado com os conteúdos que visa transmitir. A possibilidade de algo ser recortado do real - ser recortado do invisível e exposto no visível - não garante, per se, a sua entrada numa corrente de informação duradoura. No espaço mediático hodierno, o fluxo informativo desencadeia e nutre-se de forças de tensão entre acontecimentos, cuja consequência mais imediata é a da sua sobreposição temporal.

Com efeito, o escopo capital desta reflexão prende-se com a exploração das dinâmicas simbólicas que o fenómeno da corrupção - particularmente o que enreda actores públicos e vantagens pecuniárias, patrimoniais, políticas, sociais - gera na própria constituição da informação de massas. Trata-se, acima de tudo, de encontrar, nas formas de observação das práticas corruptas em geral, potencialidades estruturais afectas aos processos de mediatização da vida quotidiana, bem como de assinalar as principais transformaçóes que os mass media impóem à observação dos eventos considerados ocultos. Para tal, e tendo em vista a sua ampliação analítica, o conceito de "visibilidade" será emparelhado com o de "invisibilidade". 


\section{ObservaÇão e MEDiaTizaÇáo}

$\mathrm{Na}$ constituição das formas de observação sociais, dificilmente são discrimináveis os elementos factuais atinentes aos fenómenos observados em face dos elementos simbólicos que estruturam a própria natureza da observação. Contribuem para tal osmose, não só os fluxos de informação e as teias comunicativas, os quais em redor do fenómenos se geram, como, similarmente, as potencialidades que o médium envolvido na observação encerra, nomeadamente a sua capacidade estrutural de se tornar um veículo privilegiado das dinâmicas sociais. ${ }^{4}$ Uma vez que a inscriçâo do facto depende, simultaneamente, do poder de inscrição do médium, nesse sentido restrito, há factos que, pese embora a sua relevância social, são menos susceptíveis de aderirem à mediação. Ora, tal dependência estrutural tem uma incidência assaz marcante no registo evolutivo das formas de observação, a ponto de determinar os processos de selecção inerentes à individualização dos fenómenos observáveis.

O fenómeno da corrupção é, hoje mais do que nunca, um dos maiores exemplos desse poder de inscrição do médium. Quando, com legitimidade, se assevera que a percepção da corrupção está ligada à diferenciação dos vários sistemas sociais que constituem a sociedade moderna, nesse facto, porém, também devemos incluir a ideia de que a própria percepção se encontra já articulada pela mediatização do seu objecto. Logo, atendendo a esse carácter mediático que adquire o objecto, a expressão "percepção da corrupção" nunca deve ser considerada sinónimo linear do termo "corrupção". É sabido que a percepção da corrupção condiciona, sobremaneira, as práticas de combate aos comportamento ilícitos, assim como a identificação e categorização dos actos que são ou não considerados corruptos. Tanto nos casos em que a corrupção é livremente denunciada quanto nos casos em que é silenciada, verificase uma crescente influência da imprensa noticiosa na construção das duas dimensôes mencionadas. Não obstante o relevante papel de outros elementos

\footnotetext{
${ }^{4} \mathrm{O}$ estatuto social que determinados meios de informação possuem deve ser depreendido não só da credibilidade do emissor e do carácter fidedigno da mensagem, como, igualmente, em termos da representação dos conteúdos, das possibilidades de convergência que eles tecnicamente permitem. A título de exemplo, pode-se aventar a hipótese de que o estatuto de que, em geral, gozam os meios televisivos traz à expressão as possibilidades de convergência das formas de mediação. Como muitas vezes sucede, a exibiçáo de materiais de prova de um caso de corrupção - fotografias, escutas telefónicas etc. -, numa composiçáo jornalística televisiva, reforçam tanto o pretenso grau de veridicidade da informação quanto o grau de abrangência tecnológica do próprio meio de transmissão. É, em muito, por via dessas possibilidades de convergência que os meios audiovisuais potenciam a aura mediática da informação.
} 
institucionais e outras dinâmicas sociais - como a acção do sistema judiciário - na formação da visibilidade dos comportamentos desviantes, "diferenciação" e "mediatização" formam, portanto, uma alavanca expressiva das práticas consideradas corruptas. ${ }^{5}$

A sociedade pré-moderna, assente numa estratificação social hierárquica, conceptualizou o fenómeno da corrupção por meio do esquema binário “perfeito-corrompido". Manifestaçóes culturais, como, por exemplo, as criações artísticas, eram muitas vezes descritas e avaliadas segundo esse esquema; ou, se se quiser utilizar as fórmulas do pensamento religioso medieval, a finitude do homem, ancorada no mundus naturalis, tem uma essência corrupta, apenas ultrapassada pela entrada redentora do ser na infinitude do mundus aeternus perfeito, porque immutabilis - do deus criador.

Como pode ser inferido das análises de Jacob van Klaveren (1959, p. 204), é com a sociedade moderna e os seus mecanismos de diferenciação que, em rigor, a corrupção ganha realce na observação da própria sociedade. O mesmo é dizer: a diferenciação social exigiu mecanismos de observação da "contradiferenciaçãa" - assim como a ideia de "civilização" veio a ser contraposta à ideia de "barbárie" - que indicassem as práticas personalizadas (não diferenciadas e não contractuais) das relações sociais. ${ }^{6}$ A corrupção é, nesse sentido, uma forma de observação dos processos de modernização da sociedade, funcionando o esquema "privado-público" como sua principal lupa. Propor isso implica, igualmente, partir do pressuposto de que as práticas corruptas não se restringem à mediação operada pelo dinheiro nem, única e exclusivamente, à relação entre dois sistemas sociais distintos, como a política e a justiça.

\footnotetext{
${ }^{5}$ Resta, contudo, acrescentar que a mediatização das práticas corruptas nem sempre pode ser atribuída à intencionalidade unilateral da imprensa noticiosa. Casos há em que são os próprios actores judiciais que, violando os ditames do "segredo de justiça", dela se servem, com o duplo propósito de potenciar o seu campo de acção e, em certos contextos, desconstruir a protecção institucional e o estatuto social de que gozam os visados pelos actos ilícitos. Violaine Roussel (1998) descreve esse duplo propósito com a expressão "estratégias mediáticas" (stratégies médiatiques), as quais, na sua acepção, têm um perfil amplamente paradoxal. Se, por um lado, elas possibilitam conferir, nas esferas social e profissional, notoriedade e poder de decisão aos magistrados - e, até mesmo, "[...] de ocupar uma posição social que, antes, não lhes era acessível” (p. 267) -, por outro, a mediatização, sendo um processo que transcende o controlo dos intervenientes, póe em risco o desempenho cabal das funçóes judiciais - é, nesse segundo sentido, que a estratégia mediática pode ser, igualmente, conjecturada "[...] como uma decisão suicida do ponto de vista profissional.” (p. 270).

6 Sobre a questão da observação sistémica das práticas personalizadas, vide, especialmente, LUHMANN, 1969.
} 
Na maior parte dos casos, os dispositivos de observação da sociedade moderna encontram-se ancorados na esfera lógica da comparação. Se a cultura começou por funcionar, para o pensamento moderno, como o termo de distinção entre o bárbaro e o civilizado, a transparência é, no léxico político e económico actual, o termo de distinção entre o desenvolvimento e o subdesenvolvimento. Ambos os termos de distinção têm, porém, o fenómeno da corrupção como principal pedra-de-toque, embora seja particularmente por meio do último que ele obtém uma maior ênfase ao nível da reflexão científica e extracientífica. Há, aqui, nesse contexto semântico, uma gradual substituição da ideia de "progresso" pela ideia de "desenvolvimento". A primeira assenta, segundo o paradigma racional iluminista, na inclusão do controlo, seja este relativo às inclinaçóes do homem, seja às determinações da própria natureza; já a segunda, estando marcada pelo advento das políticas capitalistas e do mercado global, eleva a comparação aos níveis de riqueza dos países.

Por conseguinte, se o binómio bárbaro-civilizado obedece à mediação do capital cultural, o binómio subdesenvolvido-desenvolvido tende, em larga medida, a ser programado pelo capital económico. Ao nível estritamente teórico, o primeiro é suportado por observaçóes científicas que vão desde a filosofia à etnologia, alimentando-se, por sua vez, o segundo das áreas da ciência política e das ciências económicas. As semelhanças e as diferenças entre os dois binómios são várias, mas o que de mais importante de ambos releva é, justamente, a tendência objectivista inerente às formas de observação. A ideia de Hochkultur, herdeira da filosofia kantiana, assentou, quase sempre, na concepção de um campo social periférico (grupos étnicos e comunidades ditas primitivas), que, por antinomia, lhe garantisse a programação dos modelos de observação da sociedade.

Ora, à corrupção - como forma de observação - foi-lhe destinado o mesmo percurso. A divisão hierárquica entre sociedade desenvolvida e sociedade subdesenvolvida fez com que a segunda classificação servisse de negação dos ideais (não corruptos e incorruptíveis) da primeira. Como entender essa função da negação, quando todos sabemos que as possibilidades de corrupção estão longe de ser uma característica imputável, única e exclusivamente, às ditas sociedades subdesenvolvidas? A esse respeito asseverava Robert C. Brooks (1909, p. 15), logo no início do século passado, que "[...] a corrupção, nas suas formas mais insidiosas, não é um vício dos intelectos inferiores”; pelo contrário, em inúmeras situaçôes, "[...] a educação da consciência pública será 
suficiente para banir essas formas do mal ou dependerá para encontrar os meios legais para destruí-las.” É óbvio que, por trás da lógica da comparação, existe o pressuposto da "aproximaçáo", ou seja, a transição do subdesenvolvimento para o desenvolvimento gera e suporta uma semântica da "emergência”; esse conceito, aliás, depressa entrou no léxico político contemporâneo, para descrever as linhas de aproximação de um determinado país aos modelos convencionados de desenvolvimento.

A crescente mediatização das formas de observação sociais operou, nesse sentido, uma verdadeira mudança relativamente aos padrôes de avaliação do fenómeno da corrupção, bem como ao seu impacto na sociedade civil. No imaginário social do sistema jurídico, as práticas corruptas são, ainda, remetidas a um acto ilícito consumado por dois actores. Baseado na ideia de intencionalidade, divide o sistema jurídico, em geral, o acto de corrupção em duas modalidades distintas: a "corrupção activa", praticada pelo corruptor, e a "corrupção passiva", sofrida pelo corrompido. A separação entre agente corruptor e agente corrompido redunda numa epistemologia típica das concepçóes clássicas do conhecimento - a actividade do sujeito perante a passividade do objecto -, que tende a conduzir a imputação da intencionalidade do acto corrupto àquele que é designado por corruptor.

Além disso, o esquema de observação corruptor-corrompido é, em muitos contextos, excludente, uma vez que deixa de servir de pressuposto para as práticas que não envolvem directamente o agente corrompido. Podíamos utilizar, aqui, o termo autocorrupção, cunhado por Brooks (1909, p. 4), para designar todas aquelas práticas corruptas que beneficiam somente o interesse individual do corruptor, como, por exemplo, a não declaração de rendimentos nos processos de taxação de impostos. As formas de observação do sistema jurídico tendem a reproduzir os comportamentos desviantes de acordo com um modelo interaccionista da sociedade, por meio do qual são expostos sujeitos e acções, normas e desvios. Tanto o esquema binário da justiça (lícito-ilícito) como o da moral (bem-mal) da sociedade moderna incluem a pressuposição de práticas corruptas, já que lhes permite autoprogramar, de forma cabal, os códigos das acçôes que visam a regular. Tal como acontece com a imprensa noticiosa, também ambos os sistemas (justiça e moral) retiram da opacidade as próprias fontes de reproduçáo do ideário da transparência.

Todavia, como anteriormente tinha sido aventado, as formas de observação sociais dependem do poder de inscrição do médium envolvido e, no que à questão do ideário da transparência diz respeito, este acaba 
por exigir dispositivos simbólicos que melhor facilitem a sua actualização semântica dentro da esfera da comunicação. É, por via disso, que as formas de observação tendem a ganhar uma dimensão quantitativa: o médium deixa de ser governado, apenas, pela palavra; o número afirma-se como médium de comparação, facilitando as suas operaçôes e expandindo os seus campos de aplicação.

Há, com efeito, uma transferência do capital de confiança ligado tradicionalmente ao médium "palavra" para o médium "número". A função quantificadora dos números esteve, desde sempre, associada à concepção de uma ordem coerente e, por sugestáo, transparente, pois, pretensamente, nunca está tão sujeita à natureza arbitrária das interpretações - resumindo, o número promove e suporta uma observaçáo impessoal, neutra, com potencialidades generalizantes. Além do mais, e não de menor importância, tal concepção de ordem parece contrastar com a desordem provocada pelas práticas ilícitas, nomeadamente com o carácter pessoal das relações corruptas. Assim entendida, a quantificação não é, somente, mais uma simples forma de observação; ela é, conjuntamente, uma forma de purificação da própria observação.

Ainda nessa linha de argumentação, não é de estranhar que, graças a esse e outros mecanismos de observação de comportamentos desviantes, o fenómeno da corrupção tenha adquirido um imenso espectro universal, a ponto de as causas sociais que estão na sua origem serem menos conhecidas do que os seus efeitos sociais. Tal facto em muito se deve à passagem paradigmática da chamada "corrupção doméstica" para a "corrupção internacional". Os estudos sobre a corrupção acompanharam os momentos dessa transição, sendo estabelecido um primado das formas de observação político-económicas sobre as formas de observação socioculturais. Suportados por índices, os discursos da transparência e de uma pretensa regulação ética das relaçôes sociais e transacções comerciais estão na base da implementação, por parte das instituiçôes estatais, de procedimentos e legislação anticorrupçáo, sobretudo com o intento de proteger as operaçóes do mercado e o seu livre funcionamento.

\section{OCultaÇÁo e reVElaçấo}

Quando se parte do desígnio democrático da clara distinção entre privado e público, da coexistência diferencial de sociedade civil e Estado, torna-se difícil de alargar o fenómeno da corrupção às sociedades arcaicas, que assentam em regimes de organização comunitários. Se, nestas últimas, os 
mecanismos de confiança entre os seus membros são alavancados por várias formas de pertença e inclusão hierárquicas, já a sociedade moderna, pelo contrário, vê-se confrontada com a árdua tarefa de restituir a confiança no contexto do espectro funcional dos seus sistemas sociais diferenciados. Ora, as práticas corruptas apropriam-se e alimentam-se do capital de confiança ${ }^{7}$ gerado pelas vivências sociais, pois dele precisam para personalizar as relaçóes e os pactos de silêncio da corrupção.

Numa acepção ideal, o sistema jurídico, ao diminuir o grau de contingência das relaçóes entre o "eu" e o "outro", fomenta o capital de confiança, uma vez que estabiliza as expectativas decorrentes daquilo que o "eu" espera do "outro" e vice-versa. Consequentemente, embora as práticas corruptas tendam a ameaçar a contingência fundadora das expectativas sociais, isso não resulta de uma mera sobreposição das primeiras em relação às segundas, mas, antes, do engenhoso aproveitamento que é feito do capital de confiança. Por outras palavras, as relaçóes de confiança - construídas na e pela contingência social - são transpostas para modalidades de comunicação desprovidas de contingência. Há, nesses contextos performativos, uma inversão, a saber: o capital de confiança é colocado ao serviço da des-socialização dos agentes.

Com efeito, as relaçôes personalizadas, as quais caracterizam maioritariamente as práticas corruptas, promovem, inevitavelmente, a dessocialização do "eu" e do "outro", porque restringem os dois a um contexto individualista das expectativas que mantêm entre si, diametralmente oposto à visão contractualista da modernidade. A lógica assente na divisão entre interesses privados e interesses públicos é fruto da ordem contractualista que serve à formação do estado moderno. Tal como é amplamente formulado por Albert Hirschman (1977) e Quentin Skinner (1978), os desejos, vistos como formas psíquicas do homem no estado de natureza, tinham de ser transformados em interesses, para que a génese do estado social fosse exequível.

Porém, se se partir da dicotomia tradicional interesses privados-interesses públicos, ancorada na regulação dos desejos e assaz difundida pela ética e a teoria política, o fenómeno da corrupção torna-se concebível como aquele momento endémico em que a normatividade da esfera pública sucumbe perante a arbitrariedade da esfera privada. E há várias teses que defendem que, em muitos casos e contextos, a corrupção é uma reacção à suspensão dos interesses individuais, nomeadamente uma forma de desbloquear os entraves

7 Uma explanação alargada sobre a confiança nas práticas de corrupção pode ser encontrada em ALEMANN,1993. 
às relaçôes comerciais. A divisão terminológica entre "má corrupção" e "boa corrupção" tem estado na origem de várias teorias sobre a relação sistémica da modernização com a corrupção. Samuel P. Huntington (1989), por exemplo, vê nos actos de corrupção, nos ditos países subdesenvolvidos, uma forma de crescimento económico e, por consequência, de realizaçáo da própria modernização. Todavia, tais inferências parecem pôr em evidência apenas os efeitos de superfície da corrupção e não, propriamente, as suas causas sistémicas.

A distinção privado-público exige, por sua vez, a diferenciação do segredo na sociedade moderna. Numa acepção sumária, o segredo é uma retenção intencional de informação. Para Georg Simmel, a incomunicabilidade e a invisibilidade do segredo são geradoras de "confiança" no seio das relaçôes sociais; não havendo opacidade nos processos de interacção, é a própria estabilidade da sociabilidade que acaba por ser posta em causa. Seguindo uma visão positiva da retenção de informação - porque considerada, do ponto de vista sociológico, como uma forma universal, irredutível a juízos morais sobre os seus conteúdos -, assevera Simmel (1906, p. 462-463) que o segredo gera "[...] a possibilidade de um segundo mundo paralelo ao do mundo visível; este último é mais fortemente afectado pelo primeiro." Para se reproduzir, o fenómeno da corrupção alimenta-se do segredo, da retenção de todas as informaçôes que possam pôr em causa as operaçóes que estão na sua génese.

Ao contrário da economia tradicional alicerçada na troca de bens físicos, as relaçóes comerciais mediadas monetariamente vieram potenciar o carácter sigiloso das práticas corruptas - o dinheiro não compra apenas silêncios; ele esconde segredos. A introdução da mediação simbólica na economia incrementou a capacidade de "guardar segredo" sobre as operaçôes de corrupção. Além disso, a fácil circulação do dinheiro possibilita a corrupção à distância, do mesmo modo que as transacçóes monetárias permitem uma ocultaçáo dos agentes corruptos.

Desses factos redunda o que pode ser designado de espectro fantasmagórico do fenómeno da corrupção. Logo, por via da invisibilidade que as trocas monetárias permitem e preservam, a personalização típica dos actos corruptos tradicionais é ultrapassada. O médium "dinheiro" não é, meramente, uma moeda de troca, mas, também, opera enquanto forma de distinção em relação a outros comportamentos sociais. Em tais contextos, o médium de transacção é, simultaneamente, um médium de diferenciação. Num sentido inverso, porém, nomeadamente naqueles casos em que os actos de corrupção não pressupóem compensaçôes financeiras imediatas, o desaparecimento da 
acção do médium dá lugar à indiferença social do acto corrupto, tendendo este a ser incluído socialmente de maneira indiscriminada.

É, precisamente, aí, nesse espaço aberto pelas dinâmicas sociais, que os mass media tendem a actuar. A revelação de um segredo por parte dos meios de informação de massas aparece, tendencialmente - sublinhese o advérbio, porque nem sempre no que é revelado se projectam efeitos condenatórios correspondentes -, articulado sob a forma de "escândalo". O escândalo começa por ser, nesse sentido, algo secreto que é publicitado. Embora a tradição panfletária - nalguns casos, com uma índole satírica implícita revele uma apetência bastante assertiva para a exibição de eventos moralmente reprováveis, é com o aparecimento dos grandes meios de divulgação noticiosa que se constituem as características fundamentais que adjectivam um evento de "escandaloso".

A construção do domínio público, encontrando-se, cada vez mais, sob a dependência da constituição simbólica dos meios de informação, coloca os seus principais agentes sob o "regime da transparência" - regime esse, por sua vez, que redunda da pretensa transparência da própria informação. Com a revelação de uma informação que possui uma natureza secreta intencionada, o escândalo, enquanto reacção comunicativa primária, tende a multiplicar os factos que estão na base do segredo. Por outras palavras, o segredo revelado gera apetência para mais informação, para conteúdos factuais que tornem a informação ainda mais escandalosa. Todavia, a publicitação de algo secreto exige, na maior parte das vezes, uma fonte delatória que permanece em segredo e está obrigada ao silêncio. Tornar pública a informação requer tornar secreto o informador - eis uma das ramificações da diferenciação do segredo, na sociedade moderna.

Da informação de uma informação eclipsada resulta, quase sempre, uma indignação. Comparado com o efeito de "catástrofe", que gera o movimento contrário, isto é, resignação, mostra-se o efeito de "escândalo" capaz de pôr em

\footnotetext{
${ }^{8}$ Em Thèmes pour l'étude du scandale (1954), Eric de Dampierre assevera que a percepção dos eventos como escandalosos dependerá, sempre, do alcance social da comunicação que veicula os próprios eventos. Numa pequena comunidade, os efeitos do escândalo são completamente absorvidos e esbatidos pelas relaçôes interpessoais dos indivíduos. Logo, como o autor reitera (p. 331-332), qualquer evento, em si, não é suficiente para se tornar escandaloso - "[...] é preciso dar-lhe um público", constituído por opiniôes mediadas por uma "mass communication". Tal facto comunicativo alargado, também, subsiste, independentemente de "[...] o evento considerado escandaloso ser verdadeiro ou falso; o importante é que seja tido por verdadeiro.” (p. 331).
} 
jogo uma série de reacçóes condenatórias. Contudo, por que é que a reacção ao escândalo pode começar por ser moral?

Como é sabido, a moral tem uma base antropológica assaz apoiada na articulação dos sentimentos. Daí que os sentimentos de indignação expressos convidem ao juízo moral ou, por outros termos, a uma interpretaçáo moral da sua expressão. Para regular as tensôes e os conflitos intersistémicos sociais, não há nenhuma instância central que, sobrepondo-se aos demais sistemas, opere como último reduto das suas operaçóes. Nesse sentido, a moral, ainda que secundada pelo direito na sociedade moderna e desprovida da capacidade para responder, de forma cabal, à complexidade gerada pelas relaçôes entre os vários domínios e instituições da esfera pública, continua a ser idealmente vista como um potencial antídoto contra as disfunçôes sociais. A positivização do direito moderno, estando ligada à coerção exercida pelo poder estatal, fez com que a esfera moral fosse remetida à esfera psíquica dos indivíduos. O que é observado e condenado moralmente deixa de suscitar qualquer equivalência jurídica aproximada - ou, expresso numa fórmula breve: o "legal" do direito nem sempre é o "justo" da consciência.

Ora, por muito ínfima e deceptiva que seja, o escândalo possui, necessariamente, uma pregnância moral; e é, por via desse vínculo, que ele pode ser definido como "indignação moralizante", como indignação que potencia a reprodução dos próprios códigos morais. Logo, ligada ao escândalo, está uma semântica da desocultação: o "anormal" é revelado. Mas, essa revelação não manifesta, apenas, o que foge à norma. Ela revela, paralelamente, uma visão ideal e idealizante da norma e dos contextos nos quais se vislumbra inviolável - isto é, por meio dela, dá-se e reforça-se a expressão do "normal". Nesse sentido, a publicitação trazida pelo escândalo esconde mais do que revela, pois faz do anormal o espectro contrafactual do normal, alicerçando, com isso, um amplo consenso sobre o que, na maior parte das vezes, não é (nem nunca chega a ser) consensual.

Todas as formulaçôes mencionadas indicam que o escândalo potencia a actualização de uma idealização da norma e do normal, marcando, consequentemente, o espaço simbólico que tece a distinção entre ordem e desvio. Além do mais, a visibilidade que é conferida à violação da separação (ideal) das esferas pública e privada robustece o carácter individualizante do escândalo. A violação traz à expressão o comportamento anormal de um ou mais indivíduos. No entanto, para que tal suceda, não basta construir uma informação baseada no modelo "o sujeito $x$ violou a norma $y$ ". Para a 
informação ser dada sob a forma de escândalo, a sua construção noticiosa terá de transpor os limites da mera selecção e enunciação dos factos incriminatórios; a informação deve exceder o sentido da violação de uma determinada normalidade social, mostrando, para isso, aquilo que edifica a virtualidade do que é considerado normal.

Atendendo a essa particularidade, poder-se-á dizer que o escândalo se alimenta mais do carácter virtual da norma - o que é excluído da normalidade que ela produz e expressa - do que, propriamente, da sua actualização nos diversos actos comportamentais. O excluído - o anormal - é o que permite sustentar, em termos comunicativos, a edificação estrutural do escândalo. Daí que qualquer tentativa positivista de desconstrução do escândalo - como, por exemplo, circunscrever a informação somente aos factos veiculados pela informação - seja redondamente ilusória, pois, desprovidos da forma de escândalo, não há factos escandalosos em si.

\section{INVISIBILIDADE E SIMULAÇÁO}

Enquanto fenómeno mediático disruptivo, o escândalo surge como uma modalidade de reduçáo da complexidade gerada pelo fluxo de informação, porque vincula, com maior acuidade comunicativa, a percepção dos receptores à mensagem e ao próprio médium de transmissão. Logo, tal percepção deixa de estar exclusivamente centrada no objecto da mensagem. $\mathrm{O}$ escândalo tem a capacidade de se autorreproduzir, não apenas por intermédio do seu objecto factual, mas, concomitantemente, pelo excesso de comunicação que é capaz de gerar e potenciar. Os indivíduos que, no domínio público mediado pela informação de massas, se pronunciam sobre os factos e os intervenientes envolvidos no escândalo, encontram-se, da mesma forma, sujeitos aos seus efeitos.

A esse respeito, como bem salienta Niklas Luhmann (2009, p. 44), "[...] a forma como se comenta um escândalo pode potenciar outro escândalo" (Im Falle von Skandalen kann es eine weiterer Skandal werden, wie man sich zum Skandal äußert). Cada evento dito escandaloso reserva, assim, potencialidades de comunicaçáo que, independentemente da natureza do seu objecto factual, podem ser alavancadas pela natureza dos comentários que desperta, bem como pelo capital simbólico inerente aos próprios comentadores. A moralização encetada pela informação escandalosa ultrapassa a mera condenação dos comportamentos desviantes - ela abrange, potencialmente, a formação 
discursiva dos seus receptores; sendo, igualmente, verdade que, quanto maior for a teia comunicativa que a partir dela se gera, quer a repercussão quer a durabilidade mediáticas da informação tendem a aumentar.

A virtualidade moralizante de cada evento, contudo, não deve ser confundida com a especificidade das suas formas de observação. $\mathrm{O}$ escândalo é uma forma de observação sui generis. Todavia, ao contrário de muitas outras, ela não se cinge, única e exclusivamente, a uma mera apreensão valorativa do fenómeno observado; ela pressupóe, paralelamente, no âmago estrutural das suas operaçôes, a existência de uma aproximação quase-empirica à génese do fenómeno. Aliás, o escândalo tenderá sempre a aumentar, à medida que a distância do observador em relação ao objecto factual diminuir. (Daí o poder das técnicas de simulação na reconstituição do evento oculto, como, por exemplo, a de uma transacçáo corrupta encenada visualmente.)

Sob essa condição sugestiva, o observador vê-se, em certa medida, confrontado com a eclosão de um evento do qual, além de observador, é, simultaneamente, testemunha. Nesse sentido, a informação escandalosa pode gerar, nos receptores, um efeito contrário à da reprovação moral. O esbatimento da distância reflexiva entre evento e observação não anula, necessariamente, a natureza do primeiro, mas pode contribuir, de igual modo, para o enfraquecimento da capacidade de julgar. ${ }^{9}$ Por via disso, a informação sob a forma de escândalo tende a causar nos seus receptores uma indignação passiva, isto é, desprovida de uma recepção crítica - a informação impôese como substância autárquica, sem permitir espaço ontológico para a sua negação. O espaço gerado é, pelo contrário, como já tinha sido referido, o espaço para a reacçáo, para a rejeição; e, como sucede, sobretudo, nos

\footnotetext{
9 Em artigo já citado, Eric de Dampierre (1954) acrescenta que, devido à relaçáo comunicacional do escândalo com a constituiçáo de um público, há um efeito social positivo inerente à partilha de informações secretas, mas condenáveis. Dampierre só analisa o escândalo sob o prisma da condenação moral, a ponto de afirmar que, em termos colectivos, ele "cria ou activa um 'nós' [...], uma fusão parcial de consciências" (p. 336). O autor vai ainda mais longe nos seus argumentos, quando sugere que a condenaçáo pública e disseminada em larga escala de actos moralmente inapropriados fomenta "formas de sociabilidade" assaz "plenas de acção colectiva virtual" (riches en action collective virtuelle). No final, as premissas para tal argumento são dadas pela invocação do papel social das emoçōes: "[...] os fenómenos de massa e a excitação colectiva que deles redunda são reforçados, ao máximo, pelos valores sociais maltratados pelo autor do sacrilégio." (p. 336). Ora, nem sempre os eventos escandalosos são fruto de uma condenação moral, implícita ou explícita; nem sempre é possível discriminar, socialmente, o que torna o escândalo um facto social - se é, apenas e inteiramente, a reprovação moral ou se é a novidade da própria informação que se impóem como catalisadores da opinião pública. Daí que náo se possa inferir, sem reserva teórica, como tende a fazer equivocamente Dampierre, que os valores da sociedade sejam potenciados pelos processos de transformação dos eventos em escandalosos.
} 
escândalos construídos pelos meios de comunicação audiovisuais, a reacção tenderá mais a desligar-se de uma resposta crítica, quanto menor for o uso de bases argumentativas sólidas na construção da informação.

A corrupção apresenta-se, assim, como um meandro assaz sugestivo para os mass media. Tal como é aventado por John B. Thompson (2000), os meios de informação de massas, particularmente os televisivos, potenciam e expandem a visibilidade dos fenómenos, já que, dadas as suas possibilidades espácio-temporais, submetem a escrutínio todos os aspectos e todas as singularidades que constituem esses fenómenos. Todavia, a ampliação informativa expressa, somente, uma dimensão da visibilidade. No que à informação escandalosa diz respeito, Thompson apresenta, na maior parte dos casos, apenas razóes exógenas, as quais se prendem, quer com a exigência de escrutínio das actividades políticas, quer com a nova visibilidade que os seus actores alcançaram.

Numa breve reflexão sobre a articulação do escândalo com a new visibility imposta pelos meios de informação de massas, Thompson (2005, p. 43-47) interroga-se sobre os motivos da crescente prevalência dos escândalos políticos nos tempos hodiernos. Rejeitando, liminarmente, uma resposta ancorada na tese do declínio moral do comportamento dos líderes políticos, o autor expóe, inversamente, três factores capitais (tecnológico, performativo, político, na nossa interpretação), os quais contribuem para a disseminação e tipificação de eventos escandalosos. O primeiro factor - tecnológico - concerne à forma como os novos meios tecnológicos permitem conjugar a comunicação com a vigilância, encurtando o espaço de acção privado dos actores políticos e das instituiçôes a que pertencem. As mudanças no seio da cultura jornalística constituem o segundo factor - performativo -, que traz à expressão o duplo perfil de investigador e divulgador do jornalista na objectivação de realidades ocultas. Por último, o terceiro factor - político - provém das transformações da cultura política e remete, essencialmente, à gradual substituição da "ideologia" partidária pela "confiança" individualizada nos governantes, operando, aqui, o escândalo como "uma espécie de teste de credibilidade" para a inscriçáo de laços empáticos entre governantes e governados.

$\mathrm{Na}$ descrição do factor tecnológico, Thompson não implica as relaçôes da informação dita escandalosa com a própria constituição simbólica dos meios de transmissão - o tecnológico subsiste per se. Num primeiro momento analítico, o autor (2005, p. 38), seguindo o paradigma aurático de Walter Benjamin e da Escola de Frankfurt em geral, crê que, com a reprodutibilidade técnica 
da informação e a consequente "visibilidade des-espacializada" (de-spatialized visibility) dos eventos e dos seus actores, há um crescente enfraquecimento da "aura" que, em contextos hic et nunc - ou seja, de interacção e comunicação face-a-face - envolvia os líderes políticos e as instituiçôes sociais tradicionais. Num segundo momento, já com a marca paradigmática da análise dos dispositivos de poder empreendida por Michel Foucault, Thompson (2005, p. 35) acentua o carácter óptico unidimensional da visibilidade mediática, com a justificaçáo de que, perdendo-se a reciprocidade do olhar entre observados e observadores, tende a existir um incremento de vigilância sobre os primeiros.

Em muito suportadas por uma epistemologia que tem no binómio "distância-proximidade" o seu principal fundamento teórico, as propostas de Thompson encontram-se, ainda, circunscritas ao modo como a visibilidade mediática ultrapassa os limites ópticos das condiçôes empíricas espáciotemporais e permite trazer à tona aquilo que, de outra forma, permaneceria invisível. O conceito de "invisibilidade" surge, nesse contexto tecnológico, apenas como simples termo antónimo do de "visibilidade". Aliás, tal pode ser facilmente depreendido, quando o autor afirma que "[...] o visível é o que pode ser visto, que é perceptível pela visão; o invisível é o que não pode ser visto, que é imperceptível ou oculto à vista." (THOMPSON, 2005, p. 35).

Cremos, no entanto, que dos meandros do escândalo despontam outras ramificações - as quais, sendo necessariamente endógenas, resultam da própria natureza operativa dos instrumentos de produção da informação e, antes de tudo, da sua constituição simbólica enquanto meios de "massas". Quais microscópios cartesianos, tornar visível o invisível e revelar o oculto são, nessa medida, funçôes constitutivas dos meios de informação hodiernos. ${ }^{10}$ Há, por assim dizer, uma dimensão religiosa presente no desvelamento de eventos ocultos, cujo efeito é amplamente explorado pelos mass media. Convém, contudo, assinalar as diferenças entre as duas formas de mediação. Para o universo religioso, a inscrição do invisível no visível nunca chega a ser absoluta, uma vez que a omnipresença do deus não possui um correlato sensível adequado. A fé e a imaginação do crente devem preencher, no espaço

\footnotetext{
${ }^{10}$ É claro que, paralelamente, o movimento oposto tende a acontecer - tornar invisivel o que poderia ser visivel. A relevância mediática de que gozam certos eventos corresponde a uma série de elementos simbólicos estereotipados (técnicos, estéticos, morais etc.) que, sendo comuns a todos eles, lhes conferem um grau de reconhecimento alargado. É já na constituição da nossa percepção sobre os factos da informação que essa invisibilidade é inscrita; mas, se, por um lado, tal inscrição perceptual nos permite vislumbrar um campo de conteúdos individuados e relacionados, por outro, impede-nos de ver o que dele foi excluído.
} 
empírico, a lacunar visibilidade divina - a estratégia icónica é, nesse sentido, uma das formas de preenchimento.

Apesar disso, tal como se infere dos famosos Libri Carolini-publicados com o intuito de criticar muitas das teses promovidas pelo Segundo Concílio de Niceia -, a iconicidade das representaçôes religiosas deve, acima de qualquer pretensão realista, servir à sugestividade do invisível, à impossibilidade de o espiritual ser meramente traduzível no material. Na informação de massas, pelo contrário, o poder subsiste na expressão quase absoluta do invisível, que é, paradoxalmente, a um tempo, "condição" e "negação" do visível, do transparente.

Atendendo a esse duplo estatuto do invisível e respondendo às nossas indagaçôes iniciais, a corrupção gera enorme fascínio mediático e atrai as luzes do labor jornalístico porque, em parte, também reproduz as dinâmicas de visibilidade que compõem o âmago da informação noticiosa contemporânea. Tornar visível uma prática corrupta é, por consequência, actualizar e revigorar a operatividade do binómio "visível-invisível", que, hoje mais do que nunca, tende a estruturar os processos de selecção das informaçóes transmitidas, até mesmo aquelas que não são passíveis do rótulo "escândalo".

\section{Consideraçóes Finais}

Pretendeu-se mostrar que o espectro da visibilidade nos mass media, em particular na imprensa noticiosa, transcende os limites do binómio visível/ não-visível. Não se trata, única e exclusivamente, de projectar luz sobre algo que se encontra ainda votado à escuridão mediática. Mais do que isso. Tratase, como o caso da corrupção cabalmente exemplifica, de tornar visível o que é intencionalmente remetido à invisibilidade. É por meio da desocultação da informação secreta que o invisível se recria e se reproduz como dimensão da própria visibilidade mediática, acrescentando, assim, à notícia e à informação em geral, um estatuto de "revelação". A imprensa, nas suas múltiplas modalidades informativas, vê-se, hodiernamente, confrontada com a crescente expansão das plataformas de informação (e desinformação) não reguladas e não profissionalizadas, que, apesar do seu perfil heterogéneo, tendem a ter um alcance ilimitado e a produzir efeitos incomensuráveis. Emparelhar a informação com a revelaçáo afigura-se como uma forma robusta e eficaz de conservar o poder mediático dos mass media em face dos self media. 
Logo, o que a era contemporânea nos tem vindo a mostrar é que, aos mass media, não lhes cumpre, somente, a função de tornar visível a ocorrência dos eventos, de lhes dar visibilidade perante um mundo cada vez mais circundado pelas trocas de informação. Paralelamente, é possível sustentar a ideia de que os processos de informação hodiernos exigem a constituição sugestiva do espaço que precede o visivel da visibilidade - isto é, o espaço do invisível; precisamente lá, onde o evento ainda não se processou como informação, onde o evento ainda não se transformou num facto mediático. Nesse aspecto, o ancestral paradigma da "reconstituição do crime" continua a ilustrar a ideia de recriação do invisível. A simulação do que não pode ser visto, do que supostamente aconteceu, surge como uma técnica de inscrever o médium que suporta a transmissão da informação na própria configuração do fenómeno noticiado.

Ora, a capacidade de simulação do médium tende, no caso da reconstituição encenada do evento, a servir como elemento diferenciador das suas possibilidades mediáticas ante as dos demais. É óbvio que a recriação do invisível, do oculto, parece captar mais a atenção dos receptores, quando é configurada pelos meios televisivos, o mesmo é dizer: quando se torna instrumento de um regime explicitamente visual e para o qual todas as outras modalidades convergem.

Uma vez que a divulgação noticiosa das práticas corruptas nutre, concomitantemente, a recriação estética do invisível e a expressão de uma moral mediatizada, é válido, também, vislumbrar por meio dela uma legitimação daqueles fenómenos mediáticos que, embora desprovidos de real interesse social, esbatem as barreiras entre o público e o privado - como os da exposição "voyeurística" da vida íntima dos actores políticos. Se, tal como a visibilidade, também a invisibilidade obedece a critérios de construção mediática - não sendo, por extensão, a mera dimensão oculta, passiva e neutra da visibilidade -, isso implica salvaguardar a tese de que nem sempre a percepção da corrupção, considerada pelo prisma da imprensa noticiosa, tem consequências sociais, imediatas e reprobatórias. Os processos que, publicamente, ampliam os ilícitos não equivalem, por simples sugestão, aos processos que, socialmente, inscrevem a sua condenação. A geração de um fluxo comunicativo - designado de escândalo - o qual põe em jogo uma série de comportamentos verbais e não-verbais exacerbados, será, sempre, ainda insuficiente para auscultar o pulso ético da sociedade. 
BRAGA, J. Scandal and corruption: on the recreation of the invisible through Mass media. Trans/form/ação, Marília, v. 44, n. 1, p. 125-144, Jan./Mar., 2021.

\begin{abstract}
The phenomenon of corruption cannot be thought without the enclosure of its symbolic discursive possibilities. The information that, through mass media, appears articulated in the form of scandal ends up determining the structure of its factual scrutiny. The question then arises as to why corrupt practices support the discourse of scandal, as well as the substantiation of mass media as valuable tools for portraying illicit behavior. We will try to answer these questions by presupposing an aesthetics of "invisibility" inherent to media artifacts, which is in turn strengthened by the discursive potentialities of corrupt practices.
\end{abstract}

Keywords: Corruption. Invisibility. Mass media. Observation. Scandal.

\title{
REFERÊNCIAS
}

ALEMANN, U. von. Korruption ist Vertrauenssache. Capital, n. 4, p. 13-114, 1993.

BROOKS, R. C. The Nature of Political Corruption. Political Science Quarterly, v. 24, n. 1, p. 1-22, 1909.

DAMPIERRE, E. de. Thèmes pour l'étude du scandale. Annales. Economies, sociétés, civilisations, 9. année, n. 3, p. 328-336, 1954.

HIRSCHMAN, A. The passsions and the interests: Political arguments for capitalism before its triumph. Princeton: Princeton University Press, 1977.

HUNTINGTON, S. P. Modernization and Corruption. In: HEIDENHEIMER, A. J.; JOHNSTON, M.; LeVINE, V. T. (ed.). Political Corruption: A Handbook. New Brunswick. NJ: Transaction, 1989. p. 377-388.

KLAVEREN, J. van. Die historische Erscheinung der Korruption: Die Sonderentwicklung in den Vereinigten Staaten, Vierteljahrschrift für Sozial- und Wirtschaftsgeschichte, 46. Bd., H. 2, p. 204-231, 1959.

LUHMANN, N. Legitimation durch Verfahren. Neuwied-Berlin: Luchterhand, 1969.

LUHMANN, N. Die Realität der Massenmedien. 4. Auflage. Wiesbaden: VS Verlag für Sozialwissenschaften, 2009.

ROUSSEL, V. Les magistrats dans les scandales politiques. Revue française de science politique, 48. ${ }^{\mathrm{e}}$ année, n. 2, p. 245-273, 1998.

SIMMEL, G. The Sociology of Secrecy and of Secret Societies. Transl. by Albion W. Small. American Journal of Sociology, v. 11, n. 4, p. 441-498, 1906. 
BRAGA, J.

SKINNER, Q. The Foundations of Modern Political Thought. Cambridge: Cambridge University Press, 1978.

THOMPSON, J. B. Media and Modernity: A Social Theory of the Media. Stanford/ California: Stanford University Press, 1995.

THOMPSON, J. B. Political Scandal: Power and Visibility in the Media Age. Cambridge: Polity Press, 2000.

THOMPSON, J. B. The New Visibility, Theory, Culture \& Society, v. 22, n. 6, p. 31-51, 2005.

TUMBER, H.; WAISBORD, S. (ed.). The Routledge Companion to Media and Scandal. New York: Routledge, 2019.

Recebido: 01/02/2019

Aceito: 04/07/2020 